\title{
Assessing Genetic Structure and Relatedness of Jerusalem Artichoke (Helianthus tuberosus L.) Germplasm with RAPD, ISSR and SRAP Markers
}

\author{
Preeya Puangsomlee Wangsomnuk ${ }^{1^{*}}$, Sudarat Khampa ${ }^{1}$, Sanun Jogloy $^{2}$, Trin Srivong ${ }^{1}$, \\ Aran Patanothai ${ }^{2}$, Yong-Bi Fu ${ }^{3^{*}}$
}

${ }^{1}$ Department of Biology, Faculty of Science, Khon Kaen University, Khon Kaen, Thailand; ${ }^{2}$ Department of Plant Science and Agricultural Resources, Faculty of Agriculture, Khon Kaen University, Khon Kaen, Thailand; ${ }^{3}$ Plant Gene Resources of Canada, Saskatoon Research Centre, Agriculture and Agri-Food Canada, Saskatoon, Canada.

Email: "prepua@kku.ac.th, "yong-bi.fu@agr.gc.ca

Received September $8^{\text {th }}, 2011$; revised October $7^{\text {th }}, 2011$; accepted October $21^{\text {st }}, 2011$.

\begin{abstract}
Jerusalem artichoke (Helianthus tuberosus L.) is an old tuber crop with a recently renewed interest in multipurpose improvement, but little effort has been made to characterize its genetic resources. A study was conducted to assess genetic structure and genetic relatedness of 47 diverse Jerusalem artichoke accessions using RAPD, ISSR and SRAP markers. A total of 296 (87.1\%) polymorphic bands were detected from 13 RAPD markers; 92 (80\%) from six ISSR primers; and 194 (88.6\%) for nine combinations of SRAP primers. Five optimal clusters were inferred by the STRUCTURE program from the RAPD or ISSR data, while six optimal clusters were found from the SRAP data or combined marker data. Significant linear relationships between the distance matrices for all pairs of individual accessions were detected for all marker pairs and the estimated correlation coefficient was 0.40 for RAPD-ISSR, 0.53 for RAPD-SRAP, and 0.43 for ISSR-SRAP. Based on the combined data, the neighbor-joining clustering of the 47 accessions matched closely with those inferred from the STRUCTURE program. Three ancestral groups were observed for the Canadian germplasm. Most diverse germplasm harbored in the USA collection. These findings not only reveal the compatible patterns of genetic structure and relatedness inferred with three marker types, but also are useful for managing Jerusalem artichoke germplasm and utilizing diverse germplasm for genetic improvement.
\end{abstract}

Keywords: Jerusalem Artichoke, Genetic Structure, Germplasm Management, RAPD, ISSR, SRAP

\section{Introduction}

Recent years have seen an increased characterization effort directed toward the assessments of genetic structure and genetic relatedness in plant germplasm [1-3]. These assessments can not only facilitate the conservation and management of many plant germplasm collections, but also enhance the utilization of existing germplasm diversity in plant breeding [4]. The assessed genetic relatedness is critical for selection of diverse parents from less explored plant germplasm and for design of experimental crosses to widen the breeding gene pool [5]. The inferred genetic structure is essential to capture functional genetic diversity by setting up core subsets of germplasm [6] and association mapping of genes controlling complex traits [7]. However, the marker-based assessments of genetic structure and relatedness can vary, depending on the nature of molecular markers used, as different markers may sample a plant genome in different ways [8]. The variation could be substantial for a genetically heterogeneous plant with highly outcrossing and variable ploidy. Thus, an adequate attention should be paid to the performance of different molecular markers in assessments of genetic structure and relatedness $[2,8]$. Jerusalem artichoke $(\mathrm{He}-$ lianthus tuberosus L.) has been cultivated mainly for tubers since the $17^{\text {th }}$ century [9]. Its inulin-containing tubers are consumed as vegetable and can be used as raw material to produce various value-added products such as healthy food products, animal additive feed [10] and bioethanol [11]. The crop has been largely abandoned after the Second World War [12], but recently it has received a renewed interest in genetic improvement for multiple purposes [9]. Also, Jerusalem artichoke is a cold-hardy North American wild relative of the cultivated sunflower 
(H. annuus L.) and will play an increasing role in the genetic improvement of economically important traits in sunflower such as oil characters and disease resistance $[13,14]$. However, insufficient effort has been made to characterize and conserve Jerusalem artichoke genetic resources, in contrast to sunflower germplasm [15].

Currently, only several hundred Jerusalem artichoke accessions are maintained in plant germplasm collections worldwide $[9,16,17]$. These accessions represent germplasm only from a dozen or so countries and include wild and weedy accessions, landraces, or traditional and obsolete cultivars, and advanced or improved cultivars. Some efforts have been made to characterize existing Jerusalem artichoke germplasm [12,18-20]. However, these characterizations were mainly focused on phenotypic and genotypic data and would be more informative with supplementary applications of informative molecular markers. Many molecular markers have been developed for plant genetic research over the recent decades $[4,21]$. The random amplified polymorphism DNA (RAPD) [22] and inter simple sequence repeats (ISSR) [23] were among the earliest developed molecular tools used to assess plant genetic diversity due to technical simplicity and practical feasibility. For example, the RAPD and ISSR markers require no prior sequence information for the survey of plant genomes, but generally suffer from low resolution due to various issues associated with reproducibility, dominance and non-homologous DNA fragment [8], of which issues are similar to other dominant markers [24]. The sequence-related amplified polymorphism (SRAP) [25] represents another simple and reliable PCR-based marker tool for genetic diversity analysis $[26,27]$. However, these molecular markers have rarely been applied to assess genetic variation of Jerusalem artichoke [28-30]. A study was conducted to assess the genetic structure and genetic relatedness of $47 \mathrm{di}$ verse Jerusalem artichoke accessions using RAPD, ISSR and SRAP markers and to compare the congruency of the structural and relatedness assessments. It was our hope that this study can provide a useful set of diversity information not only for genetic improvement of Jerusalem artichoke, but also for understanding to what extent the different classes of molecular markers provide concordant information about the structure of populations and the relationships among individuals.

\section{Materials and Methods}

\subsection{Plant Material}

Forty-seven Jerusalem artichoke accessions were used for this study (Table 1). The studied germplasm was obtained from Plant Gene Resources of Canada (PGRC), Saskatoon, Canada and originated from Canada, USA,
France, and the former Union of Soviet Socialist Republics (USSR). It also included six accessions collected directly from the wild populations in Texas, USA.

\subsection{DNA Extraction}

Young leaf tissue was collected from at least three individual plants of one accession and bulked for DNA extraction following the Tai and Tanksley's modified method [31], which was shown to be the most effective DNA extraction method for Jerusalem artichoke [32]. The bulked tissue $(300 \mathrm{mg})$ was ground with a homogenizer and $0.7 \mathrm{ml}$ of extraction buffer $(100 \mathrm{mM}$ Tris- $\mathrm{HCl}$; pH 8, 50 mM EDTA pH 8, $0.5 \mathrm{M} \mathrm{NaCl}, 1.25 \%$ SDS, 8.3 $\mathrm{mM} \mathrm{NaOH}, 0.38 \%$ Na bisulfite) was added and mixed by vortexing. The sample was incubated at $65^{\circ} \mathrm{C}$ for $20 \mathrm{~min}$ and $0.22 \mathrm{ml}$ of $5 \mathrm{M}$ potassium acetate added and mixed well. The tube was placed on ice for $40 \mathrm{~min}$, followed by centrifugation for $3 \mathrm{~min}$. The supernatant was transferred to the new tube. The DNA was precipitated by adding 0.7 volume of isopopanol, mixed well and centrifuged for $3 \mathrm{~min}$. The supernatant was poured off and the pellet rinsed with $70 \%$ ethanol. The pellet was re-suspended in $300 \mu \mathrm{l}$ of T5E (50 mM Tris- $\mathrm{HCl} \mathrm{pH} 8,10 \mathrm{mM}$ EDTA) by briefly vortexing, and incubated at $65^{\circ} \mathrm{C}$ for $5 \mathrm{~min}$, followed by vortexing again. $150 \mu 1$ of $7.4 \mathrm{M}$ ammonium acetate were added and mixed well before centrifugation for 3 min and removal of the supernatant to the new tube. The DNA was precipitated by mixing with $330 \mu 1$ of isopropanol and centrifuged for $3 \mathrm{~min}$. The pellet was rinsed with $70 \%$ ethanol and re-suspended in $100 \mu 1$ of T5E, incubated at $65^{\circ} \mathrm{C}$ for $5 \mathrm{~min}$, and then vortexing. The DNA was re-suspended in $150 \mu \mathrm{L}$ of TE $(10 \mathrm{mM}$ Tris$\mathrm{HCl}, \mathrm{pH}$ 8.0, $1 \mathrm{mM}$ EDTA). The purity and quality of genomic DNA were assessed after digested with RNaseA (Sigma), and quantified on $1 \%$ agarose gel against know concentration of $100 \mathrm{bp}$ DNA ladder plus (Vivantis). The extracted genomic DNAs were stored at $-20^{\circ} \mathrm{C}$ until further use.

\subsection{RAPD Analysis}

Thirty-one decamer primers (Operon Technologies, Alameda, CA) were initially screened using two sets of bulked DNAs of Jerusalem artichoke to determine the suitability of each primer for the study. The first bulk consisted of 34 accessions (JA29, JA30, JA31, JA32, JA34, JA35, JA36, JA42, JA43, JA44, JA45, JA46, JA47, JA48, JA49, JA50, JA54, JA55, JA58, JA59, JA60, JA61, JA66, JA69, JA70, JA71, JA72, JA73, JA74, JA78, JA87, JA88, JA91, JA92) and the second bulk included 11 accessions (JA95，JA97，JA98，JA100，JA105，JA106，JA107, JA108, JA109, JA110, JA111). Based on their ability to 
Table 1. List of 47 Jerusalem artichoke accessions studied, along with some description, country origin and the cluster inferred with the STRUCTURE program.

\begin{tabular}{|c|c|c|c|c|c|c|c|}
\hline Acc & Description & Origin & $\mathrm{StC}$ & Acc & Description & Origin & $\mathrm{StC}$ \\
\hline JA27 & DHM-7 & Canada & 6 & JA66 & FR. MAMMOTH WHITE & USA & $5 \mid 1$ \\
\hline JA28 & DHM-13 & Canada & 6 & JA69 & TUB-364 USDA-ARS-SR & USA, Taxas & 3 \\
\hline JA29 & DHM-14 & Canada & 6 & JA70 & TUB-365 USDA-ARS-SR & USA, Taxas & 3 \\
\hline JA30 & DHM-16 & Canada & 6 & JA71 & TUB-675 USDA-ARS-SR & USA, Taxas & 3 \\
\hline JA31 & DHM-18 & Canada & 6 & JA72 & TUB-676 USDA-ARS-SR & USA, Taxas & 1 \\
\hline JA32 & DHM-19 & Canada & 6 & JA73 & TUB-709 USDA-ARS-SR & USA, Taxas & 2 \\
\hline JA34 & DHM-22 & Canada & 6 & JA74 & TUB-847 USDA-ARS-SR & USA, Taxas & 2 \\
\hline JA35 & W-97 & Canada & 6 & JA78 & FUSEA U 60 & France & 3 \\
\hline JA36 & W-106 & Canada & 6 & JA87 & $242-63$ & France & 1 \\
\hline JA42 & 75005 & Canada & 6 & JA88 & TOPINSOL 63 & USSR & 1 \\
\hline JA43 & $75004-52$ & Canada & 6 & JA91 & KIEVSKII & USSR & 1 \\
\hline JA44 & A-3-6 & Canada & 6 & JA92 & INDUSTRIE & USSR & $5 \mid 1$ \\
\hline JA45 & HM hybrid-A-4 & Canada & 2 & JA95 & NACHODKA & USSR & 1 \\
\hline JA46 & DHM-14-3 & Canada & 6 & JA97 & D19-63340 & France & 5 \\
\hline JA47 & DHM-14-6 & Canada & 2 & JA98 & $242-62$ & France & 1 \\
\hline JA48 & DHM-15 & Canada & 6 & JA100 & $105-62 \mathrm{G} 2$ & France & 1 \\
\hline JA49 & $7513 \mathrm{~A}$ & Canada & $2 \mid 6$ & JA105 & 357303 VOLGA 2 & USSR & 1 \\
\hline JA50 & W-97 & Canada & 1 & JA106 & $83-001-1(37 \times 6)$ & Canada & 5 \\
\hline JA54 & Unknown & USA & 2 & JA107 & $83-001-2(37 \times 6)$ & Canada & 5 \\
\hline JA55 & Unknown & USA & 2 & JA108 & $83-001-3(37 \times 6)$ & Canada & 5 \\
\hline JA58 & Intress & USSR & 3 & JA109 & $83-001-4(37 \times 6)$ & Canada & 5 \\
\hline JA59 & VOLZSKIJ-2 & USSR & 3 & JA110 & $83-001-5(37 \times 6)$ & Canada & 5 \\
\hline JA60 & Jamcovskij Krashyj & USSR & 4 & JA111 & $83-001-6(37 \times 6)$ & Canada & 1 \\
\hline JA61 & VADIM & USSR & 4 & & & & \\
\hline
\end{tabular}

Acc $=$ accession and label following those described in [9]. USSR $=$ the former Union of Soviet Socialist Republics. Six accessions from Texas, USA, were collected from wild populations. StC $=$ the most likely cluster inferred with STRUCTURE based on the combined marker data; the accession with two clusters means that the ancestry levels for both clusters were less than 0.5 , but the first cluster had the larger ancestry than the other cluster.

detect distinct, clearly resolved, and reproducible amplified products in the initial screening, 13 most informative primers (Table 2) were selected for further analysis.

The polymerase chain reaction (PCR) was run in final volume of 50 ng DNA template, $0.4 \mathrm{U}$ Taq DNA polymerase (Vivantis), $1.0 \mu \mathrm{l} 10 \mathrm{x}$ buffer $\left(750 \mathrm{mM} \mathrm{NH}_{4}\left(\mathrm{SO}_{2}\right)_{4}\right.$, $0.1 \%$ Tween 20, Fermantas), $1.5 \mathrm{mM} \mathrm{MgCl}_{2}$ (Fermantas), $0.2 \mathrm{mM}$ dNTPs (Vivantis), $1.0 \mu \mathrm{M}$ RAPD primer in 0.20 $\mathrm{ml}$ PCR tube. The amplification was performed in a thermocycler called "CG1-96" (Corbett Research, Germany). The amplification regime consisted of $95^{\circ} \mathrm{C}$ for $2 \mathrm{~min}$; then 45 cycles at $94^{\circ} \mathrm{C}$ for $30 \mathrm{~s}$, annealing temperature $40^{\circ} \mathrm{C}\left(36^{\circ} \mathrm{C}\right.$ for OPS04) for $30 \mathrm{~s}$, and $72^{\circ} \mathrm{C}$ for $90 \mathrm{~s}$; and a final extension at $72^{\circ} \mathrm{C}$ for $5 \mathrm{~min}$.

The RAPD amplification products were analyzed by electrophoresis on $1.2 \%$ agarose gels, run in $1 \times$ TBE, visualized under UV transilluminator, and photographed.
The PCR reactions were done three times independently. Only repeatable amplified DNA fragments were manually scored as 1 or 0 for presence or absence, respectively, for each sample.

\subsection{ISSR Analysis}

A total of 25 primers were initially screened using two sets of bulked DNAs described above to determine the suitability of each primer for the study. Based on their ability to detect distinct, clearly resolved, and reproducible amplified products from the initial screening, six most informative primers (Table 2) were selected for further analysis. The polymerase chain reaction (PCR) was run in final volume of 50 ng DNA template, $0.4 \mathrm{U}$ Taq DNA polymerase (Vivantis), $1.0 \mu 110 \times$ buffer (750 $\mathrm{mM} \mathrm{NH}{ }_{4}\left(\mathrm{SO}_{2}\right)_{4}, 0.1 \%$ Tween 20; Fermantas) $1.5 \mathrm{mM}$ $\mathrm{MgCl}_{2}$ (Fermantas), $0.2 \mathrm{mM}$ dNTPs (Vivantis), $1.0 \mu \mathrm{M}$ 
Table 2. List of 13 RAPD, 6 ISSR and 9 SRAP markers used and polymorphism detected in the 47 Jerusalem artichoke accessions.

\begin{tabular}{|c|c|c|c|c|}
\hline Primer & Sequence $\left(5^{\prime}-3^{\prime}\right)$ & Total No. of bands & Polymorphic bands (\%) & $\begin{array}{c}\text { Entropy-based diversity } \\
\text { content }\end{array}$ \\
\hline \multicolumn{5}{|l|}{ RAPD } \\
\hline OPA02 & TGCCGAGCTG & 28 & 85.7 & 5.61 \\
\hline OPA10 & GTGATCGCAG & 25 & 88.0 & 5.56 \\
\hline OPA20 & GTTGCGATCC & 25 & 84.0 & 5.69 \\
\hline OPE01 & CCCAAGGTCC & 29 & 82.8 & 5.92 \\
\hline OPE02 & GGTGCGGGAA & 31 & 90.3 & 7.65 \\
\hline OPE08 & TCACCACGGT & 22 & 95.5 & 4.64 \\
\hline OPE09 & CTTCACCCGA & 20 & 90.0 & 3.87 \\
\hline OPS01 & CTACTGCGCT & 20 & 90.0 & 3.89 \\
\hline OPS02 & CCTCTGACTG & 33 & 90.9 & 8.67 \\
\hline OPS04 & САCССССТTG & 28 & 64.3 & 4.23 \\
\hline OPS06 & GATACCTCGG & 26 & 96.2 & 6.10 \\
\hline OPS12 & CTGGGTGAGT & 32 & 84.4 & 7.03 \\
\hline OPS15 & CAGTTCACGG & 21 & 95.2 & 4.95 \\
\hline Total/Mean & & 340 & 87.1 & 5.68 \\
\hline \multicolumn{5}{|l|}{ ISSR } \\
\hline $\mathrm{P} 03$ & НVНТССТССТССТССТСС & 19 & 78.9 & 4.25 \\
\hline P06 & CACACACACACACACART & 16 & 68.8 & 1.92 \\
\hline P07 & TGTGTGTGTGTGTGTGRT & 6 & 50.0 & 0.70 \\
\hline P18 & CACACACACACACACAG & 27 & 85.2 & 5.92 \\
\hline P40 & GAGAGAGAGAGAGAGAGAYT & 21 & 71.4 & 4.24 \\
\hline P76 & GATAGATAGACAGACA & 26 & 96.2 & 6.75 \\
\hline $\begin{array}{l}\text { Total/Mean } \\
\text { SRAP }\end{array}$ & & 115 & 80.0 & 3.97 \\
\hline ME2/EM5 & $\begin{array}{l}\text { ME2: TGAGTCCAAACCGGAGC } \\
\text { EM5: GACTGCGTACGAATTCAA }\end{array}$ & 19 & 100.0 & 4.55 \\
\hline ME2/EM6 & $\begin{array}{l}\text { ME2: TGAGTCCAAACCGGAGC } \\
\text { EM6: GACTGCGTACGAATTCCA }\end{array}$ & 37 & 97.3 & 9.08 \\
\hline ME2/EM8 & $\begin{array}{l}\text { ME2: TGAGTCCAAACCGGAGC } \\
\text { EM8: GACTGCGTACGAATTCAC }\end{array}$ & 20 & 90.0 & 3.33 \\
\hline ME5/EM5 & $\begin{array}{l}\text { ME5: TGAGTCCAAACCGGAAG } \\
\text { EM5: GACTGCGTACGAATTCAA }\end{array}$ & 24 & 79.2 & 4.23 \\
\hline ME5/EM6 & $\begin{array}{l}\text { ME5: TGAGTCCAAACCGGAAG } \\
\text { EM6: GACTGCGTACGAATTCCA }\end{array}$ & 20 & 80.0 & 2.51 \\
\hline ME5/EM8 & $\begin{array}{l}\text { ME5: TGAGTCCAAACCGGAAG } \\
\text { EM8: GACTGCGTACGAATTCAC }\end{array}$ & 33 & 93.9 & 7.85 \\
\hline ME7/EM5 & $\begin{array}{l}\text { ME7: TGAGTCCTTTCCGGTCC } \\
\text { EM5: GACTGCGTACGAATTCAA }\end{array}$ & 12 & 83.3 & 3.37 \\
\hline ME7/EM6 & $\begin{array}{l}\text { ME7: TGAGTCCTTTCCGGTCC } \\
\text { EM6: GACTGCGTACGAATTCCA }\end{array}$ & 26 & 69.2 & 4.25 \\
\hline ME7/EM8 & $\begin{array}{l}\text { ME7: TGAGTCCTTTCCGGTCC } \\
\text { EM8: GACTGCGTACGAATTCAC }\end{array}$ & 28 & 96.4 & 6.03 \\
\hline Total/Mean & & 219 & 88.6 & 5.02 \\
\hline
\end{tabular}


ISSR primer in $0.20 \mathrm{ml}$ PCR tube. The amplification was performed in a thermocycler called "CG1-96" (Corbett Research, Germany). The amplification regime consisted of $95^{\circ} \mathrm{C}$ for $2 \mathrm{~min}$; then 45 cycles at $94^{\circ} \mathrm{C}$ for $30 \mathrm{~s}$, annealing temperature 45,49 or $51^{\circ} \mathrm{C}$ for $30 \mathrm{~s}$, and $72^{\circ} \mathrm{C}$ for $90 \mathrm{~s}$; and a final extension at $72^{\circ} \mathrm{C}$ for $5 \mathrm{~min}$.

The ISSR amplification products were analyzed by electrophoresis on $1.2 \%$ agarose gels, run in $1 \mathrm{xTBE}$, visualized under UV transilluminator, and photographed. The PCR reactions were done three times independently. Only repeatable amplified DNA fragments were manually scored as 1 or 0 for presence or absence, respectively, for each sample.

\subsection{SRAP Analysis}

The SRAP primers were selected based on previous reports [25]. Nine SRAP primer combinations (ME2-EM5, ME2-EM6, ME2-EM8, ME5-EM5, ME5-EM6, ME5EM8, ME7-EM5, ME7-EM6 and ME7-EM8) were initially screened using two sets of bulked DNAs described above and confirmed on their suitability for further analysis (Table 2).

A total of $10 \mu \mathrm{PCR}$ reaction mixture was composed of 1x Taq buffer (75 mM Tris- $\mathrm{HCl}(\mathrm{pH} 8.4), 20 \mathrm{mM}$ $\left(\mathrm{NH}_{4}\right)_{2} \mathrm{SO}_{4}$, and $0.01 \%$ Tween 20: Fermentas), $0.2 \mathrm{mM}$ dNTP mix, $1.5 \mathrm{mM} \mathrm{MgCl} 2,0.5 \mu \mathrm{M}$ of each primer, 0.4 unit/10 $\mu$ of Taq DNA polymerase (Fermentas, U.S.A), and $30 \mathrm{ng}$ of template DNA. PCR amplification was carried out in a thermocycler called "CG1-96" (Corbett Research, Germany) programmed for pre-denaturalization of $3 \mathrm{~min}$ at $95^{\circ} \mathrm{C}$ and 5 cycles (or otherwise stated) of 1 $\min$ at $95^{\circ} \mathrm{C}, 1 \mathrm{~min}$ at $35^{\circ} \mathrm{C}$, and $2 \min$ at $72^{\circ} \mathrm{C}$, followed by 35 cycles of $1 \mathrm{~min}$ at $95^{\circ} \mathrm{C}, 1 \mathrm{~min}$ at $50^{\circ} \mathrm{C}$, and $2 \mathrm{~min}$ at $72^{\circ} \mathrm{C}$, finally by one cycle of $5 \mathrm{~min}$ at $72^{\circ} \mathrm{C}$.

The SRAP products were analyzed by a $1.5 \%$ agarose gel electrophoresis, ethidium bromide stained and visualized by Electrophoresis Gel Photodocumentation System (Vilber Lourmat, Japan). In addition, the PCR products also were analyzed by electrophoresis on $10 \%(\mathrm{w} / \mathrm{v})$ polyacrylamide gel and revealed DNA bands by a gel silver staining. $100 \mathrm{bp}$ DNA ladder plus (Vivantis) was used as a molecular size standard. The PCR reactions were done three times independently. Only repeatable amplified DNA fragments were manually scored as 1 or 0 for presence or absence, respectively, for each sample.

\subsection{Data Analysis}

The RAPD, ISSR and SRAP data were separately analyzed for the levels of polymorphism with respect to primer by counting the number of polymorphic bands and generating summary statistics of band frequencies. Shannon's entropy was calculated following the appro- ach of Russell et al. [33] to estimate the diversity content per locus, as this estimate does not require strict genetic assumptions such as marker inheritance and sample ploidy. The entropy-based diversity content provides a measure of the effective number of alleles per marker locus [34]. These analyses were performed by using a SAS program written in SAS IML [35].

The model-based Bayesian method available in the program STRUCTURE version 2.2.3 [36-38] was used to detect population structure and to assign accessions to subpopulations. The STRUCTURE program was run 40 times for each subpopulation $(\mathrm{K})$ value, ranging from 2 10 , using the admixture model with 10,000 replicates for burn-in and 10,000 replicates during analysis. The final population subgroups were determined based on 1) likelihood plot of these models, 2) the change in the second derivative $(\Delta K)$ of the relationship between $K$ and the log-likelihood [39], and 3) stability of grouping patterns across 30 runs. For a given $\mathrm{K}$ with 30 runs, the run with the highest likelihood value was selected to assign the posterior membership coefficients to each accession. A graphical bar plot was then generated with the posterior membership coefficients. These structural data inferences were made separately for each marker type and the combined marker data.

The genetic relationships of the Jerusalem artichoke accessions were assessed using two approaches. Distance matrices based on band sharing for all pairs of the 47 individual accessions were constructed using GenAIEx 6 [40]. The relationship between the distance matrices was assessed using the Mantel's test [41] with 9999 random permutations and plotted. A neighbor-joining analysis of the 47 accessions was also made using PAUP* [42] and a radiation tree was displayed using MEGA 3.01 [43] to confirm the genetic relationships of individual accessions and to identify any genetic clustering without restriction to known characteristics. These relationship assessments were performed separately for each marker type and the combined marker data.

\section{Results and Discussion}

\subsection{Marker Polymorphism}

The characterization effort revealed variable, but compatible, polymorphism in the 47 Jerusalem artichoke accessions for three marker types, as summarized in Table 2 and Figure 1. A total of 340 RAPD bands were obtained from 13 RAPD primers; 115 ISSR bands from six ISSR primers; and 219 bands from nine combinations of SRAP primers. The number of polymorphic bands was 296 (87.1\%), $92(80 \%)$ and $194(88.6 \%)$ for RAPD, ISSR and SRAP markers, respectively. Based on the estimates 


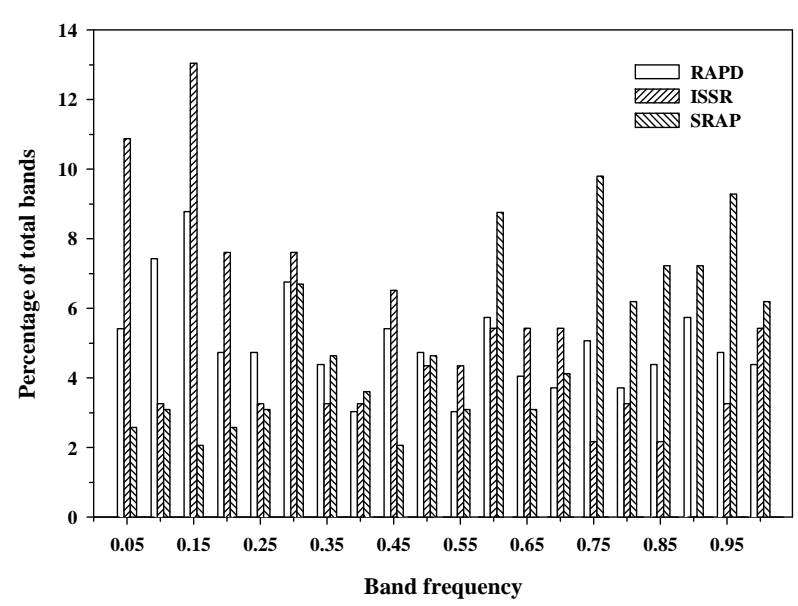

Figure 1. Band frequency spectra for RAPD, ISSR and SRAP markers detected in the 47 Jerusalem artichoke accessions.

of the Shannon's entropy per primer (or primer pair), the most informative marker type was RAPD with the Shannon entropy of 5.68 , followed by SRAP with the Shannon's entropy of 5.02 and ISSR with the Shannon's entropy of 3.97. The low information value for ISSR markers may reflect the use of a smaller number of ISSR primers.

The range of the band frequencies observed in the 47 accessions was roughly the same from 0.021 to 0.979 for three marker types, but their average band frequencies differed with $0.46,0.40$ and 0.60 for RAPD, ISSR and SRAP markers, respectively. Interestingly, an average of five RAPD bands was observed for each 0.05 interval of band frequency ranging from 0 to 1 (Figure 1). Slightly more ISSR bands with a frequency of 0.5 or smaller were observed, while slightly more SRAP bands with a frequency greater than 0.5 were found (Figure 1).

As expected for Jerusalem artichoke, an outcrossing, hexaploidy $(2 n=6 x=102)$ plant [44], a high level of genetic polymorphism was observed for these marker types [45]. Such a level of polymorphism was consistent with some reports based on various molecular markers [28-30], and compatible with those results reported in the cultivated sunflower $[46,47]$. Interestingly, the overall polymorphism was compatible over the three marker types, but the SRAP marker appeared to display a slightly higher polymorphism and detect more DNA fragments with frequencies larger than 0.5 .

\subsection{Genetic Structure}

The model-based inference of genetic structure within the 47 Jerusalem artichoke accessions by STRUCTURE considered $\mathrm{K}=2$ to 10 clusters and revealed five to six optimal clusters with the highest log-likelihoods for these three marker types and their combined data (Figure 2). First, the RAPD or ISSR markers revealed five most likely clusters with more than $80 \%$ memberships shared in corresponding clusters (Figure 2(a)). Similarly the SRAP markers or the combined marker data displayed six most likely clusters with more than $85 \%$ memberships shared in corresponding clusters (Figure 2(a)). Note that the colors or labels used for inferred clusters may differ for different markers, but a corresponding cluster inferred from two marker types was defined based on the share of the membership majority. For example, the blue and green SRAP clusters are corresponding to the red and yellow clusters in the combined data, respectively (Figure 2(a)).

The inferences of the optimal number of clusters for three marker types gained further support from the patterns of log-likelihood of the data (Figure 2(b)) and from the change in the second derivative $(\Delta \mathrm{K})$ of the relationship between $\mathrm{K}$ and the log-likelihood (Figure 2(c)). The largest average log-likelihood of -6556.3 was observed for the RAPD markers when $\mathrm{K}=5 ;-2024.8$ for ISSR when $\mathrm{K}=5$; and -3946.0 for SRAP when $\mathrm{K}=6$ (Figure 2(b)). When the three marker data were combined, the highest average log-likelihood of $-18,004.8$ was obtained when $K=6$. Similarly, the first dramatic change in the second derivative of the log-likelihoods over various Ks analyzed was occurred when $\mathrm{K}=5$ for the RAPD and ISSR markers, and when $\mathrm{K}=6$ for the SRAP markers (Figure 2(c)).

Interestingly, the RAPD and ISSR data carried similar signals of genetic structure in this germplasm set, while the SRAP data were more compatible with the combined data in the structural inference. The reason for such a discrepancy remains unknown, but it was clear that the SRAP data carried more unique information on the genetic structure of this germplasm set. In spite of this, the overall patterns of genetic structure inferred from these three marker types were highly compatible, as one of the six optimal clusters obtained from SRAP or the combined data had only two members from the former Soviet Union (JA60 and JA61) and removing these two accessions generated compatible patterns of genetic structure for all marker types (results not shown).

Based on the combined data, the average distance between individual accessions in the same cluster for six clusters were $0.346,0.254,0.138,0.158,0.239$ and 0.261 , respectively, for clusters 1 to 6 . The mean value of clusterspecific $F$ st was $0.113,0.390,0.670,0.710,0.439$, and 0.323 , respectively, for clusters 1 to 6 . The overall proportions of membership of the sample in each of the six clusters were $0.248,0.153,0.132,0.059,0.128$ and 0.279 , respectively, for clusters 1 to 6 . The detailed member- 


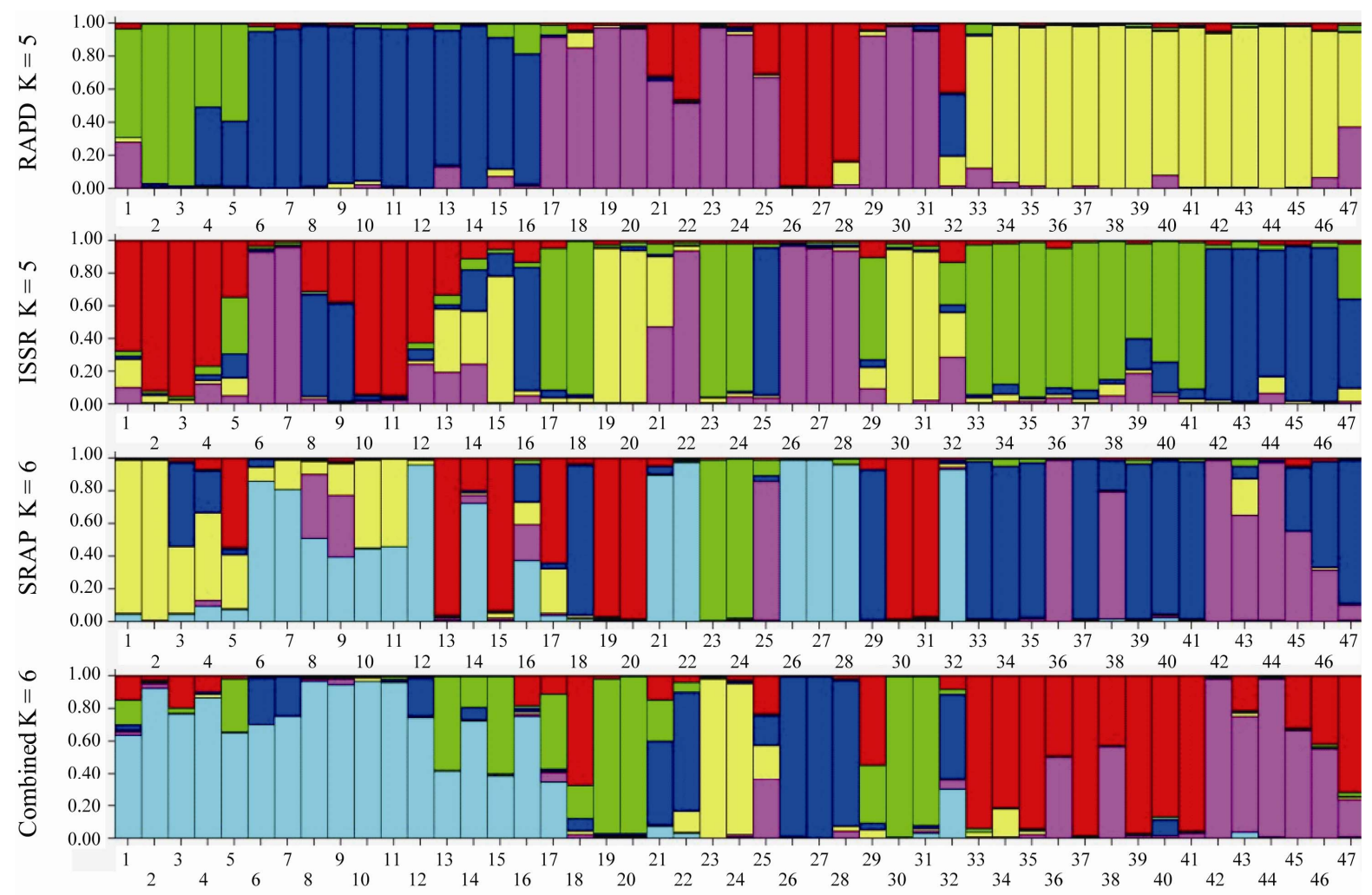

(a): Clusters inferred with STRUCTURE

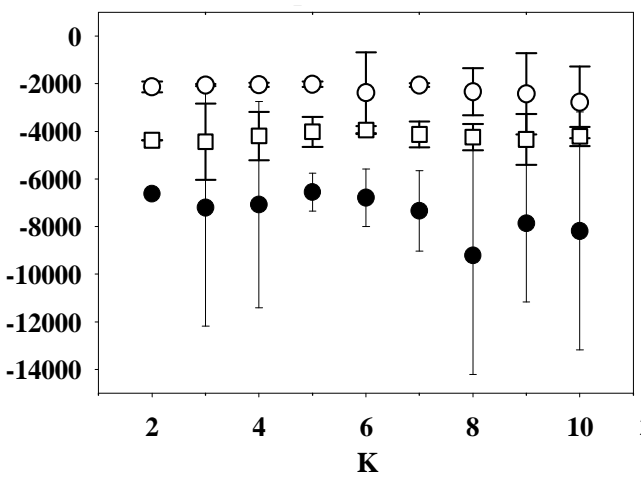

(b): $\operatorname{In}(\operatorname{pr}(\mathrm{Data} / \mathrm{K}))$

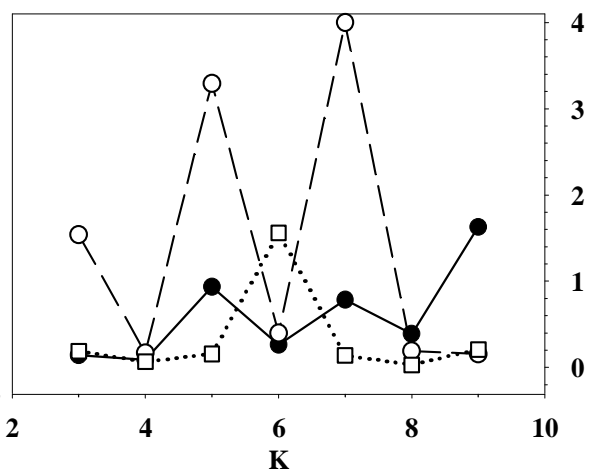

(c): $\Delta \mathrm{K}$

Figure 2. The genetic structure of the 47 Jerusalem artichoke accessions inferred with STRUCTURE and the sensitivity assessment of inference with STRUCTURE with respect to marker type. (a): the most likelihood genetic structures inferred with STRUCTURE for three marker data and the combined marker data. Each column represents an accession and the column labels from 1 to 47 matched the sequence of the accessions given in Table 1. For example, the column 4 is JA30 and the column 26 is JA69; (b) and (c): the log-likelihood profiles and the rates of change in log-likelihood for models with $\mathrm{K}=2$ to 10 for RAPD, ISSR and SRAP markers labeled with filled circle, open circle, and open square, respectively. Note that the standard deviations of the log-likelihoods for RAPD markers when $K=8$ and 10 were reduced in half for ease of illustration.

ships of the 47 accessions in each cluster were given in Table 1, which was based on the highest level of inferred ancestry for one cluster from one STRUCTURE run with the highest log-likelihood of data $(-11,792.9)$. Three accessions had the cluster membership with an ancestry level of 0.5 or less and 24 accessions displayed an ance- stry level of 0.80 or higher (Figure 2(a)).

The optimal clusters detected here might reflect the current Jerusalem artichoke gene pool, as some clusters reflected either the wild populations sampled or the consequence of long term Jerusalem artichoke breeding, particularly in Canada. However, the sampling bias may 
exist, as this germplasm set is small and may not well represent the worldwide Jerusalem artichoke germplasm. Adding other representative samples to such structural analysis would help to verify and correct the sampling bias. Thus, some caution is needed in interpretation of these optimal clusters.

\subsection{Genetic Distance}

Distance matrices based on band sharing were constructed for all pairs of the 47 individual accessions for three marker types and the relationship between the distance matrices was plotted in Figure 3. The pairwise distances based on the RAPD markers ranged from 0.091 to 0.432 and averaged 0.328 ; the pairwise distances based on the ISSR markers ranged from 0.065 to 0.5 and averaged 0.326; and the pairwise distances based on the SRAP markers ranged from 0.036 to 0.474 and averaged 0.339 . Obviously, highly significant $(P<0.0001)$ linear relationships between the distance matrices were detected for three pairs of marker type. The relationship for the pair of the RAPD and ISSR markers explained $16.4 \%$ variation with a correlation coefficient of 0.40 . The relationship for the pair of the RAPD and SRAP markers explained $28.4 \%$ variation with a correlation coefficient of 0.53 . The relationship for the pair of the ISSR and SRAP markers explained $19.2 \%$ variation with a correlation coefficient of 0.44 . However, the estimated correlation coefficients of distance matrices among these marker types are relatively low.

The revealed correlations of pairwise distance matrices, although relatively weak, were compatible among three marker types. The extent of distance matrix correlation reported here was consistent with those reported from similar studies of other plants $[48,49]$. The low correlations reflect the relatively low resolution of sampling genetic variation of a genome with these marker types, in contrast to the most informative markers such as microsatellite or simple-nucleotide polymorphism available in well-studied plant species [1,2]. However, the SRAP marker seemed to be slightly more informative than the other two marker types, as the correlations between SRAP and the other marker types were higher.

The neighbor-joining (NJ) analysis of the combined data revealed several interesting patterns of genetic relatedness (Figure 4). First, up to six clusters could be identified, but they were not well separated, even based on the information from a total of 582 DNA fragments. In spite of the low resolution, the NJ clustering matched relatively well with those inferred from the STRUCTURE program, as illustrated in Figure 4.

Two discrepancies were identified: the accessions JA45 and JA47 for Cluster 6 and Cluster 2 and the accession of JA72 for Cluster 4 and Cluster 1. Second, the six wild accessions from Texas, USA, were clustered into three groups and may reflect the different levels of ancestry among them. Third, the 24 accessions from Canada largely represented cultivated materials and were clustered into three groups, two of which the wild accessions from USA were also present. This suggests at least three ancestral
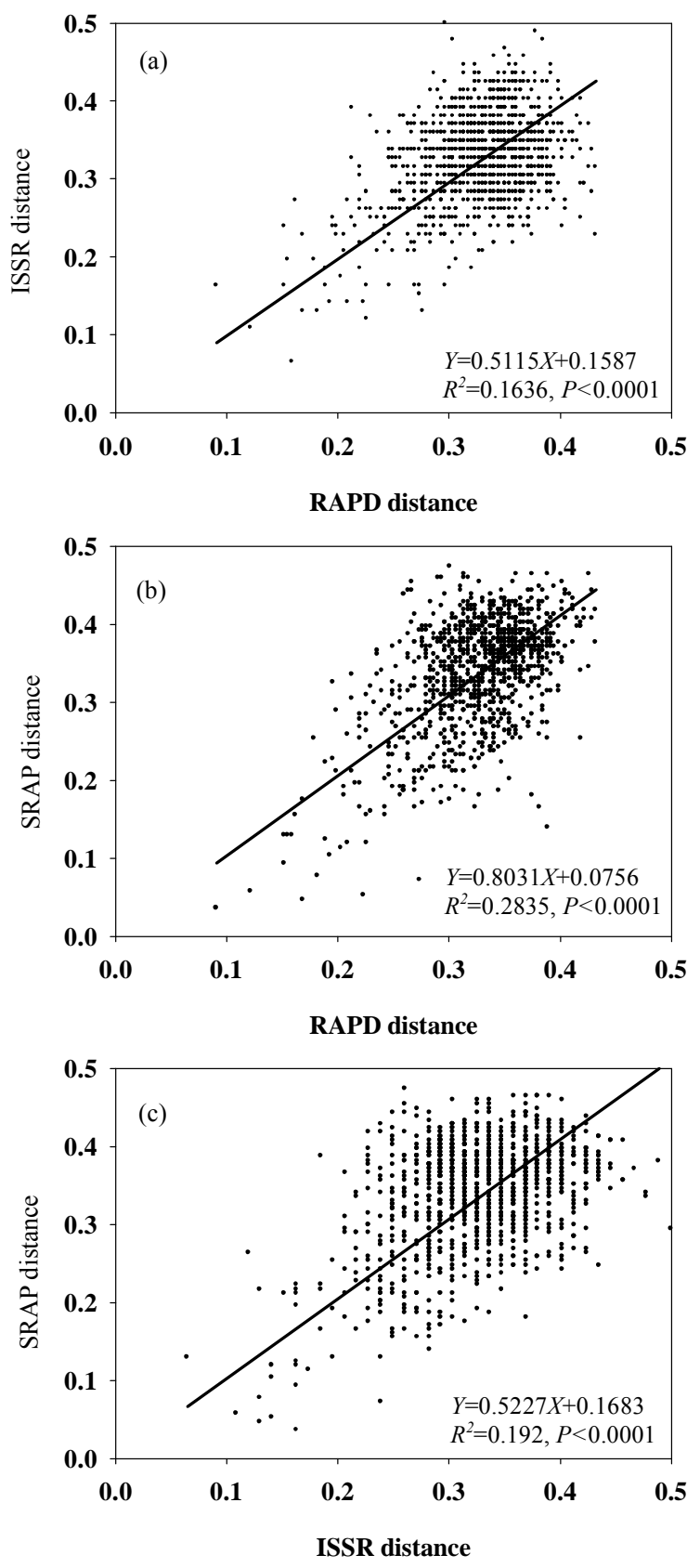

Figure 3. Correlation between genetic distances based on RAPD, ISSR and SRAP markers in the 47 Jerusalem artichoke accessions. Each point represents the genetic distance between a pair of accessions, based on band sharing of either marker. 


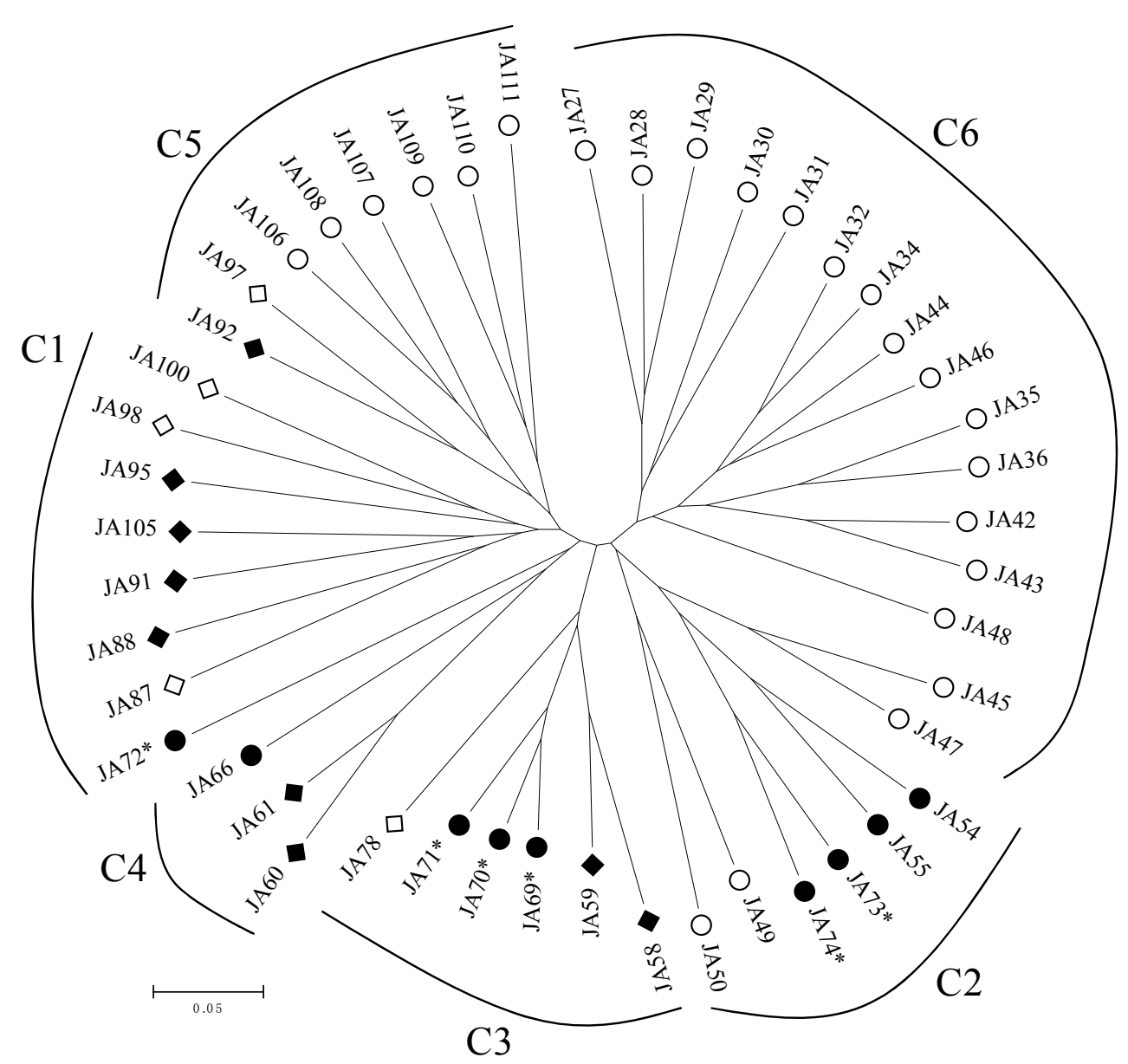

Figure 4. The Neighbor-Joining (NJ) tree displaying the genetic associations of the 47 Jerusalem artichoke accessions representing four countries. Each accession is labeled with its country origin: open circle for Canada; filled circle for USA; open diamond for France; and filled diamond for the former Union of Soviet Socialist Republics (USSR). The accession with a star was collected from a wild population in USA. Six most likely clusters inferred with STRUCTURE from the combined data were labeled with C1 - C6, except two inconsistent cases that JA50 should be located in C1 and JA66 in C5 (see Table 1).

groups for these selected Canadian accessions. Fourth, the accessions from France and the former Soviet Union were closely related to the accessions from USA, and less to the accessions from Canada. This may reflect the independent ancestral selections for Jerusalem artichoke breeding from the USA wild collection.

\subsection{Practical Implications}

The molecular markers applied here knowingly have limitations with low resolution of sampling a plant genome due to various issues associated with reproducibility, dominance and non-homologous DNA fragment [4,8]. Typically, RAPD has low reproducibility; ISSR may include nonhomologous fragments of similar size; and SRAP has a sampling bias toward the DNA fragments with an open reading frame. These technical issues are expected to introduce more deviations of sampling genetic variation among these marker types for Jerusalem artichoke with highly outcrossing and variable ploidy $[27,48,49]$.

Surprisingly, however, only some deviations were observed in this study and the revealed deviations seemed to slightly favor SRAP markers in the marker choice for a diversity analysis. For example, the SRAP markers displayed a slightly higher percentage of polymorphism (Table 2), more compatible inference of genetic structure with the combined marker data (Figure 2(a)), and the higher correlations of pairwise genetic distances with the other two markers (Figure 3). Interestingly, the three different markers revealed similarly high levels of genetic polymorphism and compatible patterns of genetic structure and genetic relatedness in these Jerusalem artichoke accessions.

The compatible diversity patterns revealed by the three different markers are encouraging for a diversity analysis 
of an under-explored plant species like Jerusalem artichoke with limited genomic resources available. The three types of molecular markers applied here are technically simple and practically feasible and could still play a role in the sampling of genetic variation in poorly known or less characterized plant species. The SRAP marker appeared to be slightly more informative than the other assayed markers and favored for further diversity analysis, but its limitation in sampling bias should also be considered in the marker choice.

The revealed patterns of genetic structure are useful for managing worldwide Jerusalem artichoke germplasm by taking the structural patterns into account in the development of diverse core subsets for further germplasm characterization and utilization. The specific core subsets [6] can facilitate the association mapping of genes controlling ecologically important traits such as inulin, oil characters and disease resistance. The revealed patterns of genetic relatedness are informative for parental selections and experimental design of productive crosses in Jerusalem artichoke breeding. Three ancestral lines were detected for the Canadian germplasm and quite distinguished from the germplasm from other countries. As expected with its species distribution, more genetically diverse accessions remain in the USA germplasm collection and a further comprehensive characterization of the USA collection would yield more useful diversity information for utilizing Jerusalem artichoke germplasm.

\subsection{Conclusive Remarks}

The multi-marker characterization of the 47 Jerusalem artichoke accessions revealed compatible patterns of genetic polymorphism, genetic structure and genetic relatedness for three marker types. The SRAP marker appeared to be slightly more informative and thus favored for further diversity analysis. A high level of genetic polymorphism was detected and six optimal groups were identified in this germplasm set. Three ancestral groups were identified for the Canadian germplasm. Most diverse germplasm harbored in the USA collection. These results are useful for managing Jerusalem artichoke germplasm and utilizing diverse germplasm for genetic improvement.

\section{Acknowledgements}

We gratefully acknowledge the Thailand Research Fund (TRF), the commission for High Education (CHE) and Khon Kaen University (KKU) for providing financial supports to this research through the Distinguish Research Professor Grant to Professor Dr. Aran Patanothai and an anonymous reviewer for his/her helpful comments on an early version of the manuscript.

\section{REFERENCES}

[1] N. Liu, L. Chen, S. Wang, C. Oh and H. Zhao, "Comparison of Single Nucleotide Polymorphism and $\mathrm{Mi}$ crosatellites in Inference of Population Structure," BMC Genetics, Vol. 6, Supplement 1, 2005, p. S26. doi:10.1371/journal.pone.0001367

[2] M. T. Hamblin, M. L. Warburton and E. S. Buckler, "Empirical Comparison of Simple Sequence Repeats and Single Nucleotide Polymorphism in Assessment of Maize Diversity and Relatedness," PLOS One, Vol. 2, No. 12, 2007, p. e1367.

[3] P. K. Ingvarsson and N. R. Street, "Association Genetics of Complex Traits in Plants," New Phytologist, Vol. 189, No. 4, 2011, pp. 909-922. doi:10.1111/j.1469-8137.2010.03593.x

[4] A. Karp, "The New Genetic Era: Will It Help Us in Managing Genetic Diversity?” In: J. M. M. Engels, V. R. Rao, A. H. D. Brown and M. T. Jackson, Eds., Managing Plant Genetic Diversity, International Plant Genetic Resources Institute, Rome, 2002, pp. 43-56.

[5] Y. B. Fu, G. W. Peterson, K. W. Richards, T. R. Tarn and J. E. Percy, "Genetic Diversity of Canadian and Exotic Potato Germplasm Revealed by Simple Sequence Repeat Markers," American Journal of Potato Research, Vol. 86, No. 1, 2009, pp. 38-48. doi:10.1007/s12230-008-9059-6

[6] A. H. D. Brown, "Core Collection: A Practical Approach to Genetic Resources Management," Genome, Vol. 31, No. 2, 1989, pp. 818-824. doi:10.1139/g89-144

[7] J. Yu, G. Pressoir, W. H. Briggs, I. V. Bi, M. Yamasaki, J. F. Doebley, M. D. McMullen, B. S. Gaut, D. M. Nielsen, J. B. Holland, S. Kresovich and E. S. Buckler, "A Unified Mixed-Model Method for Association Mapping that Accounts for Multiple Levels of Relatedness," Nature Genetics, Vol. 38, 2006, pp. 203-208. doi:10.1038/ng1702

[8] H. Nybom, "Comparison of Different Nuclear DNA Markers for Estimating Intraspecific Genetic Diversity in Plants," Molecular Ecology, Vol. 13, No. 15, 2004, pp. 1143-1155. doi:10.1111/j.1365-294X.2004.02141.x

[9] S. J. Kays and S. F. Nottingham, "Chapter 8 Genetic Resources, Breeding and Cultivars," In: Biology and Biochemistry of Jerusalem Artichoke, Taylor and Francis, CRC Press, Boca-Raton, 2008, pp. 149-240.

[10] E. A. Zaky, "Physiological Response to Diets Fortified with Jerusalem Artichoke Tubers (Helianthus tuberosus L.) Powder by Diabetic Rats," American-Eurasian Journal of Agricultural \& Environmental Sciences, Vol. 5, No. 5, 2009, pp. 682-688.

[11] G. J. Seiler, "The Potential of Wild Sunflower Species for Industrial Uses," Helia, Vol. 30, No. 46, 2007, pp. 175198.

[12] H. Serieys, I. Souyris, A. Gil, B. Poinso and A. Berville, "Diversity of Jerusalem Artichoke Clones (Helianthus tuberosus L.) from the INRA-Montpellier Collection," Genetic Resources and Crop Evolution, Vol. 57, No. 8, 2010, pp. 1207-1215. doi:10.1007/s10722-010-9560-x 
[13] R. Sennoi, S. Jogloy, W. Saksirirat and A. Patanothai, "Pathogeneicity Test of Sclerotium rolfsii, a Causal Agent of Jerusalem Artichoke (Helianthus tuberosus L.) Stem rot," Asian Journal of Plant Sciences, Vol. 9, No. 5, 2010, pp. 281-284. doi:10.3923/ajps.2010.281.284

[14] C. Breton, H. Serieys and A. Bervill, "Gene Transfer from Wild Helianthus to Sunflower: Topicalities and Limits," Oleagineux Corps Gras Lipides, Vol. 17, No. 2, 2010, pp. 104-114.

[15] J. R. Mandel, J. M. Dechaine, L. F. Marek and J. M. Burke, "Genetic Diversity and Population Structure in Cultivated Sunflower and a Comparison to Its Wild Progenitor, Helianthus annuus L," Theoretical and Applied Genetics, Vol. 123, No. 5, 2011, pp. 693-704. doi:10.1007/s00122-011-1619-3

[16] L. J. M. van Soest, H. D. Mastebroek and E. P. M. de Meijer, "Genetic Resources and Breeding: A Necessity for the Success of Industrial Crops," Industrial Crops and Products, Vol. 1, 1993, pp. 283-288. doi:10.1016/0926-6690(92)90029-U

[17] G. M. Volk and K. Richards, "Preservation Methods for Jerusalem Artichoke Cultivars," HortScience, Vol. 41, No. 1, 2006, pp. 80-83.

[18] S. Schittenhelm, "Inheritance of Agronomical Important Traits in Jerusalem Artichoke (Helianthus tuberosus L.)," Vorträge für Pflanzenzĝchtung, 1990, pp. 15-16.

[19] S. J. Kays and F. Kultur, "Genetic Variation in Jerusalem Artichoke (Helianthus tuberosus L.) Flowering Date and Duration," HortScience, Vol. 40, No. 6, 2005, pp. 16751678.

[20] R. Puttha, S. Jogloy, P. P. Wangsomnuk, S. Srijaranai, T. Kesmala and A. Patanothai, "Genotypic Variability and Genotype by Environment Interactions for Inulin Content of Jerusalem Artichoke Germplasm," Euphytica, Vol. 183, No. 1, pp. 119-131. doi:10.1007/s10681-011-0520-0

[21] I. A. Arif, M. A. Bakir, H. A. Khan, A. H. A. Farhan, A. A. A. Homaidan, A. H. Bahkali, M. A. Sadoon and M. Shobrak, "A Brief Review of Molecular Techniques to Assess Plant Diversity," International Journal of Molecular Sciences, Vol. 11, No. 5, 2010, pp. 2079-2096. doi:10.3390/ijms11052079

[22] J. G. K. Williams, A. R. Kubelik, K. J. Livak, J. A. Rafa1ski and S. V. Tingey, "DNA Polymorphisms Amplified by Arbitrary Primers Are Useful as Genetic Markers," Nucleic Acids Research, Vol. 18, No. 22, 1990, pp. 65316535. doi:10.1093/nar/18.22.6531

[23] E. Zietkiewicz, A. Rafalski and D. Labuda, "Genome Fingerprinting by Simple Sequence Repeats (SSR)-Anchored PCR Amplification," Genomics, Vol. 20, No. 2, 1994, pp. 176-183. doi:10.1006/geno.1994.1151

[24] W. J. M. Koopman, "Phylogenetic Signal in AFLP Data sets," Systems Biology, Vol. 54, No. 2, 2005, pp. 197-217. doi:10.1080/10635150590924181

[25] G. Li and C. F. Quiros, "Sequence-Related Amplified Polymorphism (SRAP), a New Marker System Based on a Simple PCR Reaction: Its Application to Mapping and
Gene tagging in Brassica," Theoretical and Applied Genetics, Vol. 103, 2001, pp. 455-461. doi: $10.1007 / \mathrm{s} 001220100570$

[26] M. Ferriol, B. Pico and F. Nuez, "Genetic Diversity of Some Accessions of Cucurbita maxima from Spain Using RAPD and SRAP Markers," Genetic Resources and Crop Evolution, Vol. 50, 2003, pp. 227-238. doi:10.1023/A:1023502925766

[27] H. Budak, R. C. Shearman, I. Parmaksiz and I. Dweikat, "Comparative Analysis of Seeded and Vegetative Biotype Buffalograsses Based on Phylogenetic Relationship Using ISSRs, SSRs, RAPDs and SRAPs," Theoretical and Applied Genetics, Vol.109, No. 2, 2004, pp. 280-288. doi:10.1007/s00122-004-1630-z

[28] B. Dozet, R. Marinković, D. Vasić and A. Marjanović, "Genetic Similarity of the Jerusalem Artichoke Populations (Helianthus tuberosus L.) Collected in Montenegro," Helia, Vol. 16, No. 18, 1993, pp. 41-48.

[29] P. P. Wangsomnuk, S. Khampa, S. Jogloy, P. Wangsomnuk and Y. Kitijataropas, "Assessment of Genome and Genetic Diversity in Jerusalem Artichoke (Helianthus tuberosus L.) with ISSR Markers," Khon Kaen Agriculture Journal, Vol. 34, No. 2, 2006, pp. 124-138.

[30] S. A. El Gengaihi, A. M. Aboul Enein, F. M. Abou Elalla and D. H. Abou Baker, "Molecular Characterizations and Antimicrobial Activities of Chicory and Jerusalem Artichoke Plants," International Journal of Academic Research, Vol. 1, No. 2, 2009, pp. 66-71.

[31] T. H. Tai and S. D. Tanksley, "A Rapid and Inexpensive Method for Isolation of Total DNA from Dehydrated Plant Tissue," Plant Molecular Biology Reporter, Vol. 8, No. 4, 1990, pp. 297-303. doi:10.1007/BF02668766

[32] T. Mornkham, P. P. Wangsomnuk, S. Jogloy, P. Wangsomnuk, A. Patanothai and Y. B. Fu, "An Assessment of Five DNA Extraction Methods for Molecular Analyses of Jerusalem Artichoke (Helianthus tuberosus L.)," Genetics and Molecular Research, in press.

[33] J. R. Russell, F. Hosein, E. Johnson, R. Waugh and W. Powell, "Genetic Differentiation of Cocoa (Theobroma cacao L.) Populations Revealed by RAPD Analysis," Molecular Ecology, Vol. 2, No. 2, 1993, pp. 89-97. doi:10.1111/j.1365-294X.1993.tb00003.X

[34] M. H. Reyes-Valdes and C. G. Williams, "An EntropyBased Measure of Founder Informativeness," Genetics Research, Vol. 85, 2005, pp. 81-88. doi: $10.1017 / \mathrm{S} 0016672305007354$

[35] SAS Institute Inc, "The SAS System for Windows V9.2," SAS Institute Incorporated, Cary, 2008.

[36] J. Pritchard, M. Stephens and P. Donnelly, "Inference of Population Structure Using Multilocus Genotype Data," Genetics, Vol. 155, No. 2, 2000, pp. 945-959.

[37] D. Falush, M. Stephens and J. K. Pritchard, "Inference of Population Structure Using Multilocus Genotype Data: Linked Loci and Correlated Allele Frequencies," Genetics, Vol. 164, No. 4, 2003, pp. 1567-1587.

[38] D. Falush, M. Stephens and J. K. Pritchard, "Inference of 
Population Structure Using Multilocus Genotype Data: Dominant Markers and Null Alleles," Molecular Ecology Notes, Vol. 7, No. 4, 2007, pp. 574-578. doi:10.1111/j.1471-8286.2007.01758.x

[39] G. Evanno, S. Regnaut and J. Goudet, "Detecting the Number of Clusters of Individuals Using the Software STRUCTURE: A Simulation Study," Molecular Ecology, Vol. 14, No. 8, 2005, pp. 2611-2620. doi:10.1111/j.1365-294X.2005.02553.x

[40] R. Peakall and P. E. Smouse, "GenAlEx 6: Genetic Analysis in Excel. Population Genetic Software for Teaching and Research," The Australian National University, Canberra, 2005. http://www.anu.edu.au/BoZo/GenAlEx/

[41] N. Mantel, "The Detection of Disease Clustering and a Generalized Regression Approach," Cancer Research, Vol. 27, No. 2, 1967, pp. 209-220.

[42] D. L. Swofford, "PAUP*. Phylogenetic Analysis Using Parsimony (*and Other Methods). Version 4," Sinauer Associates, Sunderland, 1998.

[43] S. Kumar, K. Tamura and M. Nei, "MEGA3: Integrated Software for Molecular Evolutionary Genetics Analysis and Sequence Alignment," Briefings in Bioinformatics, Vol. 5, No. 2, 2004, pp. 150-163. doi:10.1093/bib/5.2.150

[44] C. J. Swanton, P. B. Cavers, D. R. Clements and M. J. Moore, "The Biology of Canadian Weeds. 101. Helianthus tuberosus L.," Canadian Journal of Plant Science, Vol. 72, No. 4, 1992, pp. 1367-1382.

doi:10.4141/cjps92-169
[45] J. L. Hamrick and M. J. W. Godt, "Allozyme Diversity in Plant Species," In A. H. D. Brown, M. T. Clegg, A. L. Kahler and B. S. Weir, Eds., Plant Population Genetics, Breeding and Gentic Resources, Sinauer Associates, Sunderland, 1989, pp. 43-63.

[46] W.R. Lawson, R. J. Henry, J. K. Kochman and G. A. Kong, "Genetic Diversity in Sunflower (Helianthus annuus L.) as Revealed by Random Amplified Polymorphic DNA Analysis," Australian Journal of Agricultural Research, Vol. 45, No. 7, 1994, pp. 1319-1327. doi:10.1071/AR9941319

[47] G. Quagliaro, M. Vischi, M. Tyrka and A. M. Olivieri, "Identification of Wild and Cultivated Sunflower for Breeding Purposes by AFLP Markers," Journal of Heredity, Vol. 92, 2001, pp. 38-42. doi:10.1093/jhered/92.1.38

[48] L. Liu, L. Zhao, Y. Gong, M. Wang, L. Chen, J. Yang, Y. Wang, F. Yu and L. Wang, "DNA Fingerprinting and Genetic Diversity Analysis of Late-Bolting Radish Cultivars with RAPD, ISSR and SRAP Markers," Scientia Horticulturae, Vol. 116, 2008, pp. 240-247. doi:10.1016/j.scienta.2007.12.011

[49] P. Kumar, M. A. Alam, H. Singh, V. Goyal, S. Parida, S. Kalia and T. Mohapatra, "Assessment of Genetic Diversity through RAPD, ISSR and AFLP Markers in Podophyllum hexandrum: A Medicinal Herb from the Northwestern Himalayan Region," Physiology and Molecular Biology of Plants, Vol. 16, No. 2, 2010, pp. 135-148. doi:10.1007/s12298-010-0015-9 